\title{
LA "SicARESCA": DE LA agudeza Verbal AL PREJUICIO CRÍTICO
}

\author{
Óscar Wilson Osorio ${ }^{1}$ \\ Universidad del Valle
}

\section{Resumen}

El término de novela sicaresca apareció en 1995 y se le adjudica a Héctor Abad Faciolince, quien la consideró como una nueva escuela literaria, que se restringía geográficamente a Antioquia y se caracterizaba por ser protagonizada por sicarios y tener una estética truculenta y, por lo tanto, de mal gusto. Con un corpus insuficiente, el autor antioqueño relacionó la sicaresca con la picaresca, tanto en forma como en efecto evocado en el lector. A pesar de los vacíos conceptuales, el término es usado por algunos críticos literarios sin concretar su naturaleza. Para unos resultaba una escuela, tendencia, vertiente; para otros, un género o subgénero. Esto desencadenó no sólo discrepancias en la formación de corpus, sino que suscitaba contradicciones, incluso entre los mismos autores. No obstante, tras encontrar tanto semejanzas como diferencias, este texto logra definir un corpus enmarcado en lo que se denominará novela del sicariato.

Palabras clave: novela de violencia, sicaresca, picaresca, Abad Faciolince, novela del sicariato.

\section{"La Sicaresca": From verbal sharpness to critic prejudice}

\begin{abstract}
Abstrac
The term of sicaresca novel appeared in 1995 and is awarded to writer Hector Abad Faciolince, who saw it as a new literary school, which is geographically restricted to Antioquia (Colombia) and was characterized by being carried out by 'sicarios' (assassins) and has a gruesome aesthetic and, therefore, bad taste. With insufficient corpus, Antioquian author associated sicaresca to picaresque, both in form and
\end{abstract}

\footnotetext{
${ }^{1}$ Doctor en Literaturas Hispánicas y Luso-Brasileñas de The Graduate Center City University of New York, autor de libros de poemas, relatos y de la novela El cronista y el espejo (2008). Su tesis de doctorado, Novela y Violencia en Colombia: el narcotráfico y el sicariato, obtuvo el premio Gutiérrez Mané a la mejor tesis doctoral del año 2011-2012 sobre Literaturas Latinoamericanas y del Caribe Hispánico de la Universidad de Nueva York. Es profesor y director de la Escuela de estudios literarios de la Universidad del Valle (Cali).
} 
effect evoked in the reader. Despite the conceptual gaps, the term is used by some literary critics without specifying its nature. For some it was a school, a trend, a shed; for others, a genre or subgenre. This triggered not only differences in the formation of corpus, but aroused contradictions, even among the same authors. However, after finding both similarities and differences, this text does define a corpus framed in what is called the novel of sicarios (assassins).

Keywords: novel of violence, sicaresca, picaresque, Faciolince Abad, novel of sicarios (assassins).

\section{Los lastres de una ocurrencia}

En 1995 Héctor Abad-Faciolince acuña la expresión "sicaresca antioqueña" diciendo que se trata de una "nueva escuela literaria surgida en Medellín" (p. 515). ${ }^{2}$ No menciona las obras que constituirían esta sicaresca, ni es claro qué textos tiene en mente a la hora de plantear el surgimiento de una escuela literaria, pero en lo atinente a la novelística antioqueña con tema de sicario se conocían Pelaito (1991) y Virgen (1994). Pudo referirse también a la literatura con protagonistas narcotraficantes (cuyos productos más visibles eran $\mathrm{La}$ mala hierba (1981) y Leopardo al sol (1993) -de la costa Atlántica-, El Divino (1986) -del Valle del Cauca-, pero estas anécdotas no se desarrollaban en Antioquia ni sus escritores son de esta región. Además, los protagonistas de esta literatura no eran sicarios, como lo prescribe Abad-Faciolince. No parece lógico afirmar el surgimiento de una escuela literaria teniendo en cuenta solo la exitosa novela de Vallejo y la desconocida novela de Gaviria. Es probable que en la construcción del concepto se hubiera deslizado a otros textos no literarios, que desde hacía algún tiempo se estaban haciendo cada vez más populares en Colombia. Me refiero al libro No nacimos pa semilla de Alonso Salazar (1990), a la película Rodrigo D: no futuro de Víctor Gaviria (1990) y a la telenovela Cuando quiero llorar no lloro (1991), adaptación de la novela homónima (1970) del venezolano Otero Silva. ${ }^{3}$ Estos tres

${ }^{2}$ Abad-Faciolince, H. "Estética y narcotráfico". Número 7. II-III (1995). Una versión ampliada se publica en Revista de Estudios Hispánicos 42 (2008): pp. 513-518. Cito con número de página por esta última versión.

${ }^{3}$ Esta telenovela fue reelaborada para Telemundo, con guion de Gustavo Bolívar, el mismo autor de Sin tetas no hay paraiso, única novela que Abad-Faciolince nombra en el apartado "Los hampones literarios" (haciendo sí la salvedad, entre paréntesis, que este escritor no es un hampón ni un mafioso). Sin embargo, la "salvedad" se disuelve cuando califica de "hampones literarios" a 
productos y Virgen tuvieron gran acogida entre lectores y espectadores. Me parece que es esta acogida masiva de productos con tema de sicario lo que genera el rechazo de Abad-Faciolince y le inspira el término sicaresca para aludir a "la fascinación por el sicario, que también empezó a padecer la literatura" (p. 515).

El artículo en el cual aparece el término hace una crítica de la cultura del narcotráfico que, a juicio del autor, ha hecho visible y generalizado una estética cuyo "mal gusto es un vicio nacional" (p. 513), y cuyas características centrales "en lo literario el gusto por la truculencia, y en lo pictórico la pasión por el exceso, serían influencias mafiosas" (p. 516). Es precisamente esta condición estética, según Abad-Faciolince, la que orienta la narrativa con tema de sicario, al que "ha empleado la literatura como nuevo tipo en relatos a veces buenos, a veces horribles, casi siempre truculentos" (p. 515).

Quizá alentado por la acogida del término, vuelve sobre esta denominación en una entrevista concedida cuatro años después a Renato Ravelo. En esa ocasión, añade que la sicaresca antioqueña se asemeja a la picaresca española por ser narración en primera persona y porque este personaje es visto "con cierta benevolencia y tolerancia" en dichos textos. Evidentemente, la necesidad de darle apoyo argumentativo a su juego verbal lo hace forzar demasiado los conceptos. Salvo el hecho que ambas beben de los mundos marginales, la relación entre sicaresca y picaresca debe reducirse a un brillante concepto, un juego de agudeza por aproximación fónica. Pero detengámonos brevemente en los tópicos que señala.

Afirmar como constante formal el uso de la primera persona en las novelas del sicariato no tiene ningún fundamento. Ni Virgen ni Pelaíto, las dos novelas antioqueñas con tema de sicario que se conocían por la época de la primera versión del texto de Abad-Faciolince, están narradas en la voz de la primera persona del sicario. Si nos atenemos al corpus completo de esta novelística, a las novelas que se publicaron después de esta primera versión y antes de que el autor publicara la

los autores que, según él, hacen "culto sórdido a la vulgaridad y a los hampones o a sus hembras de plástico" (p. 517). Llevar al ámbito de la creación el tema de los delincuentes le parece a Abad-Faciolince que pone en una similar esfera delictiva a los autores de dichos textos con los delincuentes que los protagonizan. Esto es, a todas luces, una injusta exageración. 
segunda versión ampliada del texto (2008), la afirmación sigue siendo errónea. De las siete novelas que componen el corpus de esta narrativa, dos tienen narradores subordinantes en tercera persona: El sicario y Morir. Las otras cinco tienen narradores en primera persona, pero únicamente en Sicario esa primera persona es la voz del sicario. En Sangre también aparece la primera persona en la voz del sicario, pero junto a la tercera persona que es voz narrativa subordinante. En las otras tres novelas quien narra en primera persona es alguien cercano al sicario: el hermano en Pelaito, el enamorado en Rosario, el amante en Virgen. Incluso en el caso de los narradores en primera persona sicarios de Sicario y Sangre, la arquitectura narrativa propone la mediación de un escritor que es narratario del sicario y organizador de su discurso, por lo que esa primera persona aparece contaminada por la edición del periodista. ${ }^{4}$ En fin, en las novelas de este corpus no hay una misma propuesta narrativa $\mathrm{y}$, mucho menos, que se corresponda con la primera persona de la novela picaresca, que es la voz del protagonista pícaro. La diferencia entre los narradores pícaros de la picaresca y los múltiples narradores (en primera y en tercera persona; sicarios y representantes de la sociedad hegemónica) de la novelística del sicariato hace estas narrativas radicalmente distintas y afecta la percepción de los mundos construidos por ellas y la recepción de sus productos.

Los narradores en tercera persona de la novela del sicario pertenecen a la sociedad normalizada y exhiben rasgos de una cultura más "elevada" y, en la mayoría de los casos, de una distancia moral que condena el mundo del sicario. Los narradores en primera persona de esta novelística también dejan clara la diferencia (casi siempre superioridad moral) entre ellos y el sicario. Estos narradores o bien pertenecen a otra clase social y evidencian su superioridad cultural respecto de los sicarios o esa distancia se construye a través de la estrategia narrativa de vincular a un narratario investigador que ejercerá como primera instancia narrativa al organizar el discurso de su entrevistado sicario. Es lo que ocurre en Sangre y Sicario: la voz en primera persona del narrador sicario está en un registro que no se corresponde con el entorno social al que pertenece, está contaminada por la voz del narrador periodista que lo

${ }^{4}$ De este asunto me ocupo con más detalle más adelante, analizando la función del narrador en la novela de sicarios. 
entrevista y que pertenece a otra clase social y a otro entorno cultural. La excepción es Pelaito, cuyo narrador en primera persona pertenece a las comunas y tiene una plena identificación social, moral, axiológica y cultural con el sicario, a pesar de que su discurso está mediatizado por un narratario entrevistador que organiza el material narrativo en la voz del entrevistado. Salvo en Pelaito, es una constante la distancia de orden cultural, social y/o moral entre el narrador y el sicario. No importa si son narradas en primera o en tercera persona, la instancia narrativa enfatiza la distancia entre el narrador y el sicario. En la picaresca, en cambio, la narración autobiográfica tiene el propósito de enfatizar la identificación entre narrador y pícaro.

Esto tiene efectos nada despreciables. La separación entre narrador y sicario genera un primer efecto de distanciamiento que nos indica la diferencia entre el mundo de los lectores (identificado con el del narrador $)^{5}$ y el de los sicarios, y un segundo efecto (simultáneo) que nos hace entender que ese mundo marginal, visto inicialmente como una anomalía, es cercano, hace parte de nuestro entorno a través de múltiples vasos comunicantes. Este distanciamiento-acercamiento produce asombro y rechazo por ese universo de sordidez y un creciente interés por un mundo que vamos entendiendo más cercano de nuestra vida de lo que siempre nos negamos a aceptar. En la picaresca, el narrador-pícaro ayuda a producir el efecto de distancia ya no entre el universo del narrador y el del actor (el pícaro), sino entre el universo del texto y el del lector. Este acercamiento-distanciamiento (movimiento inverso al de la literatura del sicariato) deja en el lector la certidumbre de que este mundo ajeno y divertido no es el suyo sino una cierta abstracción de efectos didácticos. La novela del sicariato nos ayuda a entender el mundo que habitamos, la picaresca nos enseña cómo no debemos comportarnos en él. ${ }^{6}$

\footnotetext{
${ }^{5}$ Partiendo del supuesto de que no debe haber muchos sicarios que lean esta literatura o, mejor, que la inmensa mayoría de los lectores no somos sicarios.

${ }^{6}$ Sin embargo, algunos autores persisten en los intentos por darle solidez conceptual al juego verbal de Abad-Faciolince e intentan señalar elementos comunes entre la picaresca y la sicaresca. María Fernanda Lander, por ejemplo, encuentra dos elementos fundamentales: la pobreza como "el resorte que impulsa las acciones de los personajes" y "la violencia de la vida urbana" (2007, p. 167). Así, concluye Lander, “en ambos géneros los personajes adquieren la condición metonímica del sujeto urbano socialmente marginado (2007, p. 167). Camila Segura lo plantea de esta forma: "El pícaro y el sicario comparten su corta edad, el entorno urbano, la capacidad para servir como
} 
En cuanto al tema de la benevolencia con el delincuente, la crítica se ha referido abundantemente a la fascinación por el sicario. Me parece que dicha fascinación no es identificación y que precisamente esta técnica narrativa de una primera persona distinta, cercana a la vez que lejana, al "fascinante" sicario es un elemento central para que entremos en la sordidez de estos mundos con una actitud menos prevenida. Además, en la novelística del sicariato los resultados de esas vidas delictivas son siempre aleccionadores y abundan los juicios negativos, las sanciones morales, los ejemplos correctores, los finales fatales. No obstante, en Rosario Tijeras y Sangre ajena esta fascinación por el sicario sí conduce a una actitud de benevolencia y tolerancia con el criminal, que, además, termina exculpándolo de sus crímenes.

También en algunas de las novelas del narcotráfico hay una cierta benevolencia y tolerancia con el narcotraficante e incluso en unas pocas hay una actitud festiva y aprobatoria del fenómeno y sus protagonistas. Es posible decir algo parecido también de las narrativas audiovisuales. Me parece que una de las diferencias fundamentales entre la narrativa literaria y las narrativas audiovisuales sobre el sicariato y el narcotráfico es precisamente la falta en las segundas de la actitud distanciadora del narrador de las novelas del sicariato. En los textos audiovisuales sobre el tema, la focalización cero contribuye a generar cierta identificación con el sicario o el narcotraficante y ahí sí se filtra una actitud de "benevolencia y tolerancia".

En todo caso, tratar de entender cómo se produce el delincuente; cuáles son sus motivaciones y sus determinaciones sociales, familiares y culturales; cómo actúa, piensa y habla; cómo tramita su relación con el entorno y cuáles son los hilos sociales que nos unen a él no es "benevolencia y tolerancia". Es, por el contrario, la actitud y el conocimiento necesarios para empezar a cambiar las condiciones de su génesis social. Eso no es aprobarlo o justificarlo, sino dejar la estremecedora constancia de que el mal está entre nosotros. Silenciar la

radiografías sociales, la encarnación de contradicciones de un tejido social marcado por la hipocresía y la negación, el padecimiento de la marginalización y la exclusión, la crisis entre valores y consideraciones pragmáticas en medio del entorno hostil” (2004, p. 115). Todo eso es cierto, pero esas características que señalan las autoras no son exclusivas del sicario, sino que son expresiones asociadas a la pobreza y la marginalidad urbanas. La literatura está llena de personajes abyectos que tienen todas esas características y que no son sicarios. 
representación (literaria, periodística, mediática) de la realidad pavorosa del sicario sería quedarnos con la experiencia cotidiana de la muerte y la descomposición social sin ver tras el arma detonada la compleja e indeseable sociedad que todos vamos construyendo o quedarnos con la fría e insustancial persistencia de las estadísticas y el asombro que ellas nos producen.

En el nuevo apartado "Los hampones literarios" de la versión ampliada del 2008, Abad-Faciolince fustiga el éxito comercial de los testimonios y textos periodísticos aparecidos por la época, escritos por los delincuentes, por sus familiares o por los que él denomina "periodistas mercenarios". La noción de una estética mafiosa se amplía aquí para calificar una producción narrativa escrita o dictada por los delincuentes mismos.

Se puede, entonces, concluir que el término sicaresca define, en su origen (en la acuñación de Abad-Faciolince) una narrativa producida en Antioquia o sobre Antioquia (y más específicamente en Medellín), que es truculenta y cuyos personajes son sicarios. Esta narrativa se inscribe en una producción textual que va más allá de la literatura de ficción y que está orientada por la que el autor considera una estética mafiosa. Ahora bien, aunque el autor explicita su definición en un par de renglones, el contexto en el que aparece el término ofrece la posibilidad de ampliar la noción de sicaresca a la narrativa del narcotráfico, definición que, de hecho, es la que han asumido algunos críticos.

El término porta un sentido peyorativo y expresa el repudio que dicha producción textual colombiana le produce a Abad-Faciolince. Es, pues, una designación nacida del rechazo. La sicaresca es entendida en su designación inicial como una literatura deleznable. ${ }^{7}$ No es, como quiere Lander, "que los escritores han bautizado, medio en broma, medio en serio, la 'sicaresca'” (2007, p. 175). Es que tal designación está definida en su origen por un profundo desprecio.

\footnotetext{
${ }^{7}$ A propósito de este criterio y de la relación establecida por el juego verbal entre picaresca y sicaresca, estas valoraciones de Abad-Faciolince suenan a las de Gregorio Marañón en el prefacio -mejor decir antiprólogo- al Lazarillo de Tormes: “Allí aprendió la suya el gran Quevedo, ejemplo insigne de todas las excelsitudes del pensamiento, pero, ¡ay!, también de esa secta no exclusiva de España, pero en España singularmente poderosa, del literato ilustre que por serlo, se cree dispensado de las normas del respeto y de la medida sociales (...) Además de este sentido radicalmente inmoral, la picaresca tuvo una influencia pesimista, lamentable, en el alma española. El triunfo de lo que no es justo produce siempre una impresión depresiva en la sociedad" (1969, pp. 15-16).
} 
Una revisión de la literatura publicada antes y después del artículo de Abad-Faciolince deja constancia de que la narrativa literaria con tema de sicariato y/o narcotráfico ha resultado muy prolífica en Colombia y ha dejado algunas novelas de excelencia literaria sobre las cuales no aplican los calificativos de "truculentas" y orientadas por el "mal gusto" de una estética mafiosa. Dada la perspectiva crítica elegida para este trabajo, no se hace una indagación sobre la literariedad de dichas obras, pero dejo constancia de la aprobación que sobre algunas de ellas ha hecho la crítica especializada, la obtención de varios premios internacionales de literatura por algunos de sus títulos, su aparición en editoriales de prestigio y la traducción a distintos idiomas de varias de estas novelas. No resulta, pues, apropiado el término sicaresca para designar esta literatura porque la descalificación y el repudio están implícitos en tal designación y porque la preinscribe en una estética truculenta, la constriñe al territorio antioqueño, no precisa los lindes entre literatura con tema de sicarios y literatura atinente a otras delincuencias. No obstante, la crítica ha acogido el término sin mayores miramientos y, en ocasiones, de manera confusa.

\section{La "sicaresca" en la crítica literaria}

Walde (2000) retoma esta designación para titular su artículo "La sicaresca colombiana. Narrar la violencia en América Latina". En esta breve reseña comenta Virgen y otros textos con tema de sicarios: la película Rodrigo D: no futuro, el libro No nacimos pa'semilla ${ }^{8}$ y el documental Diario de Medellín de Catalina Villar. Aunque no hace ninguna aproximación conceptual a lo que entiende por sicaresca, queda claro que esta designación desborda lo literario e incluye otras narrativas de la violencia que se ocupan del sicario. Al año siguiente, en su artículo "Novela de sicarios y la violencia en Colombia", vuelve a aquello de sicaresca antioqueña y menciona de nuevo Virgen e incluye Rosario. Podríamos decir que estos dos artículos son la carta de confirmación de esta denominación en el terreno de la crítica. Walde incluye en la sicaresca unas narrativas no necesariamente literarias y las adscribe a

\footnotetext{
${ }^{8}$ Este es un texto hibrido. Casi todo el libro está compuesto por crónicas de estos muchachos marginales de Medellín, pero la última parte es un ensayo que propone una interpretación socio-cultural del fenómeno del sicariato en la capital antioqueña.
} 
la región de Antioquia (más concretamente a Medellín), pero no usa el término de manera despectiva, ni parece valorar esta narrativa como truculenta.

Lander retoma el término sicaresca, aunque advierte que otros críticos prefieren llamarla "narcorrealismo", y plantea que esta literatura así designada constituye un nuevo género literario surgido en Colombia que se ocupa de representar la violencia asociada al narcotráfico. Para Lander, "the common thread among these novels is the exploration of the violence committed by 'sicarios,' or killers for hire, who were initially recruited by drug traffickers" (2003, p. 76). Como parte de esta narrativa literaria incluye Virgen, Rosario, Hijos de la nieve, Sangre y Comandante Paraiso. En su primer trabajo sobre el tema, no precisa Lander los elementos que le hacen considerar dicha literatura como constituyente de un género literario, pero señala que "in spite of the diverse topics and techniques explored in these works, what they do have in common is the examination of a disarticulated national community resulting from violence" (2003, p. 76) e insiste en que "the 'sicaresca' is a new and distinctive discourse" (2003, p. 77). Aunque el interés central de este trabajo es analizar la novela de Vallejo, hace una breve introducción al asunto de la sicaresca, en el que ya no aparece la restricción a una literatura antioqueña. En un trabajo posterior, sin embargo, procura profundizar en esa narrativa y concluye "que la nueva novela colombiana que escoge el tema de la violencia que genera el narcotráfico -y que los escritores han bautizado, medio en broma, medio en serio, la "sicaresca"- define su condición genérica a partir de la noción de que la violencia última del sicario reside en la ausencia de arrepentimiento" (2007, p. 75).

Si Walde hace uso del término sin prestar mayor atención a su validez o a sus alcances y Lander precisa su condición de nuevo género a partir de la constante impenitencia que define la construcción novelesca de Rosario, Virgen y Sangre, Jácome (2006) procura hacer una defensa de esta nominación y una definición del corpus que cabría bajo la misma. Para ello, parte de la definición de Abad-Faciolince, cuyas "generalidades hacen pensar en la sicaresca como un grupo de textos diversos, que incluiría narraciones fílmicas y escritas, testimoniales y noveladas producidas en la región de Antioquia, cuyas características comunes 
son el protagonismo del joven sicario al servicio del narcotráfico y su violencia" (pp. 1-2). Luego retoma el primer texto de Lander, para anotar que esta autora plantea un "corpus bastante amplio si no disímil, ya que incluye, además de las narraciones sobre sicarios, dos novelas sobre el tráfico de drogas" (p. 2).

Para resolver el problema de estas generalizaciones, Jácome precisa que la sicaresca designa "al corpus conformado por textos novelados sobre los jóvenes asesinos al servicio del narcotráfico en la ciudad de Medellín" (p. 2). ${ }^{9}$ Hay, al menos, tres errores en esta afirmación: uno: no todos los sicarios de esta literatura son de Medellín; dos: no todos los sicarios trabajan para el narcotráfico o exclusivamente para narcotraficantes; tres: no todos los sicarios referidos en estas novelas son jóvenes. ${ }^{10}$

${ }^{9}$ Fiel a esta afirmación (central en la definición del corpus que ella propone para la sicaresca), Jácome increpa a Alberto Quiroga por su "tono obtusamente regionalista que, en este caso, insinúa que sólo los antioqueños escriben sobre los sicarios de Medellín, ignorando que en 1997 había aparecido la novela de Collazos, escritor de la costa Pacífica, y a principios del 2000 la de Arturo Álape, escritor nacido en Cali" (p. 160). Podría parafrasearse esta misma cita para argumentar que no es adecuada la definición que la misma Jácome propone, pues insinúa que solo los colombianos escriben sobre los sicarios colombianos, ignorando que en 1991 habia aparecido la novela de Vázquez-Figueroa, escritor español. Habría que precisar que el sicario protagonista de Sangre (que Jácome menciona en la argumentación) es un muchacho de Bogotá, aunque inicia y desarrolla su actividad sicarial en Medellín. Además, la novela El sicario, del autor español ya mencionado, tiene como protagonista a un sicario bogotano y la novela Sicario (que menciona Jácome) tiene como protagonista a un sicario de Cali. Anotemos que tanto la novela de Bahamón Dussán, como la novela de Vázquez Figueroa son anteriores a las de la saga antioqueña. Me parece inadecuado restringir la novela del sicario (que estos críticos llaman sicaresca) a una narrativa escrita por autores antioqueños y, menos aún, a una narrativa sobre sicarios de Medellín. El mismo Jácome, siendo consciente de lo equivocado del criterio, según se infiere de esta cita, se deja arrastrar por él.

${ }^{10} \mathrm{Sin}$ embargo, esta noción de juventud asociada al sicario es de uso extendido y más en la década de los ochenta y noventa, cuando estos asesinos se hicieron más visibles, como bien lo anota Carlos Ortiz: "A la connotación usual del castellano, de asesino a sueldo, los colombianos hemos adicionado al término en el lapso de apenas cinco años una connotación de edad que ha llegado a serle esencial: el sicario es un joven o un adolescente. Aún más, por la fuerza de los hechos (puesto que los contratos para matar, en estos años, han puesto la mira efectivamente en esas edades), el término sicario sufrió entre nosotros una brusca evolución hasta significar hoy, ya no el asesino pago, sino el asesino joven, así obre por propia cuenta e iniciativa en sus venganzas, rebusques o bravuconadas" (1991, p. 60). Así lo recoge una buena parte de los críticos que se ocupan del tema: "Sicarios are young men between the ages of 15 and 25 -working in groups- who specialize in earning their money from contract killings" (Waldmann, 2007, p. 600); "En suma, el arquetipo del sicario es el de una persona joven que adolece de la figura paterna. Sobrevive en un hogar disfuncional, usualmente llevado por una madre soltera que eventualmente intenta reorganizar su vida afectiva con alguien que termina convirtiendo al sicario en un intruso en su propio hogar" (Molina, 2010, p. 254); "El protagonismo del joven sicario al servicio del narcotráfico y su violencia" (Jácome 1-2); "Joven asesino a sueldo que se moviliza en moto" (Ospina, p. 36); "Adolescentes colombianos con el oficio de asesinos a sueldo nacidos de la pobreza, el narcotráfico, y del caos 
Con base en la definición que propone, Jácome establece que la novela sicaresca es un "género literario nuevo (...) conformado por La Virgen de los sicarios (1994) de Fernando Vallejo, Morir con papá (1997) de Óscar Collazos, Rosario Tijeras (1999) de Jorge Franco Ramos y Sangre ajena (2000) de Arturo Álape" (p. 3). En su argumentación sobre la delimitación de este corpus, Jácome precisa que "a nivel general, el elemento que da cohesión a varias novelas bajo el rótulo de 'sicarescas' es su temática" (p. 8) y que la primera novela que se ocupó de dicha temática fue El sicario. ${ }^{11}$ Sin embargo, no incluye esta novela en su corpus argumentando que presenta una serie de deficiencias de construcción. Estas deficiencias serían la causa, junto con lo limitado de su edición, de que no se pueda incluir en su estudio. Luego dedica varias páginas a tratar de establecer los límites de la sicaresca a partir de su diferenciación con otras narrativas con tema de sicario que no tienen el estatuto de novela. Entre ellas menciona El Pelaito que no duró nada, que excluye de su corpus porque, según ella, pertenece al género del relato testimonial. ${ }^{12}$

Los criterios que aduce para excluir las novelas de Bahamón y Gaviria son discutibles. La primera, "la novela pionera" (en sus palabras), es eliminada con argumentos de carácter estético: la novela no se incluye dentro del corpus porque es literariamente deficiente. La valoración de la calidad estética es un criterio aceptable para que la novela no haga parte del canon literario o para que perdamos nuestro interés en su lectura o análisis, pero no parece un criterio aceptable para desconocerla como parte de un corpus (menos, si es la obra pionera) que existe bajo la premisa de su relación con el referente: la novela del sicariato reúne las novelas que tienen al sicario como protagonista, independiente de su calidad estética. Por vía de la censura estética podríamos reducir este corpus a una o a ninguna novela (si nos atenemos, por ejemplo, al juicio de Abad-Faciolince). Sería, por ejemplo, muy complicado encontrar ar-

sociopolítico" (Pobutsky, 2010, p. 579). Sin embargo, en la narrativa del sicariato y el narcotráfico aparecen sicarios mayores, incluso viejos.

${ }^{11}$ Jácome data la novela de 1990, pero la primera edición, de Editorial Orquídea, es de 1988.

${ }^{12}$ Claudia Ospina se refiere a obras que "exploran desde la perspectiva testimonial" (79), en las que incluye No nacimos pa'Semilla, Ganzúa y Pelaito. Riahna Weakley lo entiende como "textos que intentan imitar o parodiar el formato testimonial para lograr en el lector un efecto parecido al del testimonio mediato" (p. 145), criterio que aplica a Sangre. Lander se refiere a Sangre como una "novela pseudotestimonial" (2007, p. 173). 
gumentos estéticos para privilegiar Sangre de El sicario. Pero lo fundamental es que si la novela del narcotráfico y/o del sicario se definen por su temática (como la misma Jácome lo afirma) no parece apropiada una reducción del corpus determinada por criterios estéticos.

Jácome excluye Pelaito porque la considera un testimonio. Además de las tremendas dificultades (y ello es evidente en sus argumentaciones) para trazar los lindes entre la narrativa testimonial y la novela basada en testimonios, ${ }^{13}$ dos elementos me parecen importantes para mantener este texto dentro del corpus. El primero, que la información obtenida en la investigación periodística de Gaviria fue objeto de un proceso ficcional para hacer guion cinematográfico y después hubo un segundo proceso ficcional que dio como resultado la novela. Así lo explica el autor en la contraportada del texto. Este doble proceso es ratificado por la aclaración que pone como complemento de su título: "Basado en el relato de Alexander Gallego". La palabra "basado" no solamente da cuenta de la fuente de Gaviria sino de la distancia entre el resultado de su investigación y el texto final. "Basar" significa, según la Real Academia Española, "asentar algo sobre una base, fundar, apoyar". "Basado" no es "igual o fiel a la fuente", significa que el relato de la fuente sirvió de base, de fundamento, para el proceso creativo del novelista. Esto se confirma cuando el autor Gaviria la registra como una novela, es publicada como una novela y la crítica la refiere como una novela. Descalificar la decisión editorial, la del autor y la aceptación de la crítica requeriría argumentos muy sólidos que no están en la argumentación de Jácome. ${ }^{14}$

\footnotetext{
${ }^{13}$ Weakley aclara que "los rasgos del género se matizan con cada obra por lo que no existe una idea canóniga o fija de la literatura testimonial. En su lugar, los editores defienden sus propias versiones del género al describir en el prólogo sus motivaciones y propósitos del proceso de creación de su texto" (2005, p. 144).

${ }^{14}$ Cuando nos ponemos frente al terreno pantanoso de la definición del género novela, es bueno recordar las ideas de Maupassant (1971) en el prólogo de su novela Pedro y Juan cuando cuestiona al crítico que "se atreve a escribir también: 'Esto es una novela y aquello no lo es', me parece que está dotado de una perspicacia que se asemeja mucho a la incompetencia" (p. 17). Y continúa: “¿Cuál de estas obras es una novela? ¿Cuáles son esas famosas reglas? ¿De dónde proceden? ¿Quién las ha establecido? ¿En virtud de qué principio, de qué autoridad y de qué razonamientos? // No obstante, parece ser que esos críticos saben de una manera cierta, indudable, lo que constituye una novela y lo que la distingue de otra que no lo es. Esto, sencillamente, significa que sin ser productores están agrupados en una escuela y rechazan, a la manera de los mismos novelistas, todas las obras concebidas y realizadas fuera de esa estética"(p. 18).
} 
Por esta vía tendríamos que desconocer como novelas muchos otros textos publicados como tales. Recordemos que, y muy especialmente en esta literatura asociada a fenómenos históricos, las correspondencias inmediatas entre la realidad y los textos que la representan son muchas. Algunas de ellas están soportadas en un trabajo documental, periodístico y testimonial, y son tan evidentes sus correspondencias y vínculos con los referentes en lo real que sus autores y editores se ven impelidos a aclarar que estas historias y personajes son ficción y que las semejanzas con la realidad son mera casualidad. Algunos ejemplos de este afán están registrados en los paratextos de novelas como La mala hierba; Leopardo al sol; Quitate de la vía, Perico. Además de las novelas que remiten a través de paratextos a investigaciones previas, también suele ocurrir que las novelas usen la técnica del testimonio como estrategia narrativa. Así lo señala Weakley: "En la escritura literaria de fecha reciente en América Latina, el discurso testimonial ha sido usado y manipulado por muchos textos literarios. Dichos textos intentan imitar o parodiar el formato testimonial para lograr en el lector un efecto parecido al del testimonio mediato" (2005, p. 145).

Como "preámbulo" de la sicaresca, Jácome sitúa dos corrientes: "Las novelas antioqueñas que recrean el ambiente de las zonas marginales de Medellín y aquellas con el narcotráfico como tema central de la trama” (p. 36). A propósito de la relación de la novela del sicariato con estas últimas anota:

"Aunque indirectamente las novelas describen el trabajo de las bandas al servicio del negocio, es solo hasta la aparición de la novela sicaresca en los noventa cuando el joven asesino entra como protagonista en la literatura y de manera contundente en la novela colombiana, conformando un género tangencialmente tributario de la narco-novela, pero singular no solo en los temas sino en sus técnicas de representación que tienen que ver más con las del género testimonial (2005, p. 41)."

Aileen El-Kadi (2007) registra el uso que la crítica hace de tres designaciones para la literatura de ficción que se ocupa del tema de la violencia asociada al narcotráfico y al sicariato: "La sicaresca colombiana (Erna von der Walde), la novela sicarial colombiana (Camila Bonnet), 
la narco-novela (Chole Rutter)" (p. 2). El-Kadi dice que la crítica ha anunciado el nacimiento de un "subgénero", sin dar más información sobre qué define este subgénero ni cuáles son los críticos que lo consideran dentro de esta categoría, ni por qué razones. Dentro del corpus que menciona como narraciones de ficción llama la atención la inclusión de Noticia de un secuestro de García Márquez. ${ }^{15}$

Gabriel Inzaurralde, retomando a Von der Walde, recurre al término para afirmar que "La Virgen de los sicarios inauguró, quizá sin llegar a serlo ella misma, un nuevo género de literatura popular: La 'sicaresca colombiana' (Von der Walde, 2000: 222-223)” (p. 50). Como representantes de esta literatura cita las mismas novelas que la lista del primer ensayo de Lander (Rosario, Hijos de la nieve, Sangre, Comandante) y añade Satanás de Mario Mendoza. Llama la atención el inciso aclarativo "sin llegar a serlo ella misma", que sustrae la novela de Vallejo del corpus que ella misma inauguraría. No explica el tesista la razón de ello y es evidente que no le interesa hacerlo. Sin embargo, se puede inferir que la aclaración de Inzaurralde implica la sustracción de la novela de Vallejo de la valoración negativa que su inclusión dentro de la sicaresca (esa literatura deleznable) comporta. De todas maneras, el término es tomado aquí muy desprevenidamente, sin atención por sus alcances, lo que se hace evidente al incluir en el corpus de dicha novelística, no solo las novelas que trabajan sobre la violencia del narcotráfico sino, como en el caso de Satanás, novelas que narran otras violencias.

Otro autor que hace eco del término sin ahondar en él es Héctor Fernández L'Hoeste (2008): “An ingenious derivative of the Spanish designation for the picaresque, the word sicaresca is a generic denomination for cultural products associated with the depiction of paid as-

\footnotetext{
${ }^{15}$ Habría que anotar que los límites entre el periodismo literario y la literatura (o, en el caso particular al que nos referimos, entre el reportaje literario y la novela) están bastante diluidos. Así lo señala Alejandro López (2003) en su planteamiento sobre la "indefinición aparente" de este género: "Hablar de periodismo literario implica adentrarse en un terreno cuyos contornos no son nítidos de manera alguna" (p. 18). Sin embargo, hay una frontera intransitable entre la literatura y el periodismo: la ficción. Si el proyecto narrativo se somete al compromiso de fidelidad con los hechos, a la no ficción, estamos ante un texto periodístico, un reportaje que, si usa las herramientas propias de la literatura en el proceso de textualización, se puede considerar un reportaje literario. Ese es el carácter del texto de García Márquez: Noticia de un secuestro ha sido concebido y publicado como un texto periodístico y, por ello, el contrato con el lector pasa por el compromiso de fidelidad a los hechos. Este carácter (de creación y editorial) lo excluye del corpus de textos de ficción.
} 
sassins or sicarios. (...) Novels like La Virgen de los sicarios (1994), Rosario Tijeras (1999), Hijos de la nieve (2000), Sangre ajena (2000), and Comandante Paraíso (2002) exemplify this trend" (2008, p. 543). No obstante, esta definición sirve solo al propósito de enmarcar dentro de una tendencia narrativa más general las realizaciones cinematográficas que son su objeto de estudio. A juicio de Fernández L’Hoeste estas filmaciones constituyen un subgénero cinematográfico, implicando que este subgénero haría parte del género narrativo más amplio de la sicaresca.

Maite Villoria Nolla (2002) también usa el término sin prestar mayor atención por el mismo. Sin embargo, las dos veces que lo menciona, deja patente que está acogiendo un uso generalizado: “Considero inútil caracterizar lo que se ha venido definiendo como sicaresca colombiana por la referencia exclusiva al tipo 'real' del sicario o el arquetipo del sicariato cotidiano que construyen los medios. (...) Entre las novelas de la así llamada 'sicaresca'...” (p. 110). Como otros críticos, la autora referencia Virgen, Rosario, Morir y Sangre.

Fonseca (2009) actualiza el término para referirse a una "vertiente" (p. 25) del corpus más amplio de la narco-narrativa. El autor entiende la narco-narrativa como producto "de un fenómeno global como es el tráfico de drogas" (p. 7) que, "a través de la representación literaria, registra y revisa las implicaciones sociales y económicas de esta nueva escala de valores" (p. 8), textos con "características formales y temáticas similares que participan de una modalidad narrativa transnacional [pero que] no constituyen un género en particular [porque] desde el punto de vista formal, las narco-narrativas utilizan una gran variedad de discursos y estrategias narrativas que impiden su definición a partir de las reglas de género"(p. 9). ${ }^{16}$ De esta literatura hacen parte aquellas novelas "que señalan la posibilidad que tienen los jóvenes sicarios de lograr acceso a las dinámicas del consumo de bienes de lujo. Entre las novelas que desarrollan esta dinámica tenemos la denominada novela del sicariato o 'sicaresca' (Abad-Faciolince)" (p. 46).

\footnotetext{
${ }^{16}$ A pesar de esta definición, en la misma página el autor dice: "Quiero evocar el diálogo que tiene el nuevo género de las narco-narrativas con su pasado literario" (p. 9). Que refiera como género una literatura que un párrafo antes ha rechazado como constitutiva de un género da cuenta de cómo la referencia a estos corpus en términos de géneros o subgéneros se va volviendo un uso cotidiano que no remite a formulaciones específicas.
} 
Omar Rincón (2009) usa el término en un ensayo en el cual hace una reflexión en torno a la cultura del narcotráfico y sus manifestaciones en la música, en la televisión, en el lenguaje y en la arquitectura: "¿Y qué es la sicaresca? Un nuevo tipo de relatos que habita la fascinación por los sicarios, la truculencia y la pasión por el exceso" (p. 151). Para Rincón, esta sicaresca es la estética del sicario, que se manifiesta en narrativas que aprovechan la fascinación que esta provoca en un país de "narco.cultura": "Esta estética de la sicaresca va a aparecer en $L a$ virgen de los sicarios (Fernando Vallejo, 1994) y Rosario Tijeras (Jorge Franco, 1999), exitosas obras literarias que se convierten en exitosas películas. Otras dos obras fundamentales de la sicaresca son la ya citada No nacimos pa 'semilla (Alonso Salazar, 1990) y El Pelaito que no duró nada (Víctor Gaviria, 1991)" (p. 152).

Rincón anota que esta estética de la sicaresca remite a la juventud sicarial y es diferente de la estética del narcotraficante: "Para quedar claros, la sicaresca es la estética del joven, es una épica del éxito rápido, vivir a millón y morir joven. Otra cosa es la narco.estética, que es la expresión de los patrones, que es el gusto socializado en los adultos, que es la marca Colombia más actual" (p. 153). Aunque no se hace un desarrollo de esta noción de la estética sicaresca manifestada en los relatos que cita (salvo la mención rápida de la heredada idea de la truculencia), es importante la diferenciación entre la sicaresca y la narco.estética, en la medida en que plantea la diferencia (muchas veces olvidada) entre el ámbito del narcotráfico y el del sicariato.

Pobutsky acoge el término sin prevenciones y define esta narrativa, a partir del análisis de Virgen y Rosario, como un "subgénero literario dentro de lo que se denomina la literatura del narcotráfico" (2010, p. 567), aunque luego la refiere como "género" (2010, p. 579).

Salvo la tesis de Jácome (2006), el término es usado por los críticos sin detenerse en las implicaciones conceptuales de dicha categorización para esta literatura. Abad-Faciolince (2008) la denomina una "escuela", otros autores plantean un "género", hay quien lo reduce a un "subgénero", quien habla de una "vertiente", quien lo define como una "tendencia". Algunos de los críticos han usado estas categorizaciones sin mayores explicaciones, pero quienes han intentado argumentar dicha 
definición genérica terminan forzando constantes formales. Si aquello que comparten estas narrativas es el tema del sicario y el narcotráfico, estoy de acuerdo con Fonseca en que no constituyen un género en particular. En ese sentido, me parece que lo útil es precisar los alcances y las implicaciones de una denominación para esta narrativa y examinar si las que hasta ahora se han impuesto resultan satisfactorias.

Cinco elementos incorpora Abad-Faciolince en la denominación sicaresca: 1. escuela literaria surgida en Medellín, 2. narrativa producida en Antioquia y/o sobre Antioquia, 3. truculenta 4. los personajes son sicarios, 5. es una literatura deleznable porque comporta una narco-estética. Walde (1997) comparte con Abad-Faciolince su consideración sobre la condición local de dicha literatura, su ampliación a otras narrativas no literarias y la presencia del sicario protagonista, pero no la acusa de truculenta ni la prejuzga. Lander (usa indistintamente sicaresca y narco-realismo) comparte la idea de una literatura que representa la violencia ejercida por sicarios (asociada al narcotráfico), pero la entiende más allá de la limitación local de una saga antioqueña y, al igual que Walde, no la rechaza por su temática. El-Kadi (2007) usa los términos sicaresca, narco-novela y novela sicarial para referirse a la literatura colombiana que trata el tema de la violencia asociada al narcotráfico. Jácome (2006) restringe el término a un corpus de cuatro novelas, mantiene la idea de Abad-Faciolince de que es una literatura que representa la violencia ejercida por jóvenes sicarios en Medellín y entiende la sicaresca como un género tangencialmente tributario de la narco-novela. Contrario a Abad-Faciolince, ella no usa el término con función irónica y reconoce el valor literario de las novelas que componen su corpus. Inzaurralde (2007), Fernández L’Hoeste (2008) y Villoria Nolla (2002) acogen el término sin detenerse en el examen de sus implicaciones. Fonseca (2009) entiende la sicaresca como una variante de la narco-narrativa, la variante que se ocupa específicamente de los protagonistas sicarios. Rincón (2009) reserva el término para hablar de una estética, la del joven sicario (diferente a la narco.estética del narcotraficante), que se materializa en unos relatos "truculentos". Pobutsky (2010) entiende la sicaresca como un subgénero (y un género) cuyos protagonistas son adolescentes sicarios y que hace parte de la literatura del narcotráfico.

Como se ve, el término sicaresca no es usado en una sola dirección 
$\mathrm{y}$, en general, los críticos lo toman de manera desprevenida para aplicarlo a las narrativas asociadas a la violencia de los sicarios, a la representación literaria de las violencias asociadas al narcotráfico y a otras violencias, o para nombrar una estética que se materializa en las obras con tema de sicario. Esto cuando no caen en la tentación de una definición de género o subgénero para dicha literatura, que seguramente parte de la asimilación del género picaresca implicado en la denominación sicaresca. Aunque Abad-Faciolince intenta en su entrevista con Ravelo, anotar un par de confluencias formales entre la picaresca y la sicaresca (narración en primera persona y benevolencia hacia el delincuente), tales constantes en realidad no soportan un mínimo examen. Además, aunque los críticos que se han ocupado de analizar a fondo y con rigor esta literatura no participan del criterio de que la misma es una literatura deleznable, el rechazo inherente al juego verbal que dio origen a dicha denominación persiste en una amplia zona de reseñadores, comentadores $\mathrm{y}$, en general, en ciertos ambientes académicos que miran con desprecio esta literatura. ${ }^{17}$

\section{La novela del sicario versus la sicaresca: definición del corpus}

El trabajo de Jácome tiene el mérito de proponer un corpus de la "sicaresca", ateniéndose a la idea de que esta novelística se define por la elección del tema del sicariato en Medellín. Por ello, reduce el corpus a cuatro obras: Virgen, Morir, Rosario y Sangre. Me parece que tal restricción puede ayudar a sostener la idea de una literatura local ("la sicaresca antioqueña"), pero desestima el importante asunto de que la primera novela cuya anécdota tiene como eje central y exclusivo las peripecias de un sicario no es antioqueña (como ella misma lo reconoce en su trabajo) y su protagonista sicario es de Cali, y que otra novela (anterior a las de la saga antioqueña) fue escrita por un español y su protagonista sicario es de Bogotá. Tal reducción perpetúa, además, la idea falsa de que el sicario es paisa, como si la realidad pavorosa del sicariato no hubiese hecho presencia en todo el territorio nacional, con especial fuerza en aquellos lugares en los que actuaban los principales

\footnotetext{
${ }^{17}$ Jácome señala, en el apartado "la novela sicaresca en el reseñismo cultural de la globalización" (pp. 155-164), la falta de profundidad y conocimiento de las reseñas que abundan sobre esta narrativa.
} 
carteles de la droga. Esta restricción limita los alcances de la categoría que ella quiere establecer y no ayuda en la tarea de hacer una lectura más completa y rigurosa de la literatura con tema de sicariato en Colombia.

Es cierto que Medellín fue la ciudad donde se hizo más visible el fenómeno del sicariato y donde tuvo su efecto más devastador en la descomposición del tejido social: muchos jóvenes de las comunas de la capital antioqueña y de los municipios circunvecinos entraron a hacer parte de las bandas de delincuentes juveniles, ${ }^{18}$ la mayoría de los sicarios que participaron en los magnicidios que acabaron con la vida de candidatos presidenciales, ministros, senadores y demás personalidades de la vida nacional eran oriundos de dicha ciudad; las escuelas de sicariato fueron fundadas en Antioquia. Sin embargo, no podemos olvidar que los sicarios han hecho parte de las estructuras criminales de todas las mafias de las drogas en Colombia y que en otras regiones se han desarrollado carteles del narcotráfico con un inmenso poder criminal que, incluso, mantuvieron (como en el caso del Cartel de Cali) una guerra abierta contra el Cartel de Medellín. Esta guerra empezó en los años ochenta y, no debería ser necesario decirlo, se hizo a través de sicarios contratados en Cali y Medellín. ${ }^{19}$ Es por esta presencia del sicario en diferentes regiones del territorio nacional que aparece esta figura en las ficciones de novelas cuya diégesis se desarrolla en ciudades distintas a Medellín.

Por otro lado, Jácome explica su elección de la palabra sicaresca diciendo que ha "optado por este término en lugar de novela del sicariato en razón de que este último puede sugerir erróneamente la presencia de textos literarios escritos por sicarios" (p. 2), pero mantiene el de literatura del narcotráfico para referirse a la literatura con tema de narcotráfico. Si seguimos su argumentación, tendríamos que concluir, entonces, que la literatura del narcotráfico es escrita por narcotrafican-

18 "La organización de jóvenes en bandas crecía como bola de nieve. Las autoridades militares y de policía registraron, entre 1985 y 1990, un total de 153 bandas en el Valle de Aburrá, 122 ubicadas en Medellín, 1en Itagüí, 8 en Envigado, 19 en Bello y 11 en la Estrella. Sin embargo, esta información es parcial. Sólo en el municipio de Bello, según la alcaldía municipal, operaban más de 50 bandas" (Jaramillo \& Salazar, 1992, p. 89).

${ }^{19}$ En los primeros años de los ochenta, Medellín casi duplicaba a Cali en muertes violentas. No obstante, las cifras de muertes por arma de fuego en Cali eran ya muy altas y había una elevada participación de sicarios en ellas (véase: Camacho Guizado y Guzmán Barney) (1990). 
tes, cosa que está lejos de las intenciones de la autora y, por supuesto, de la verdad. Sin necesidad de entrar en explicaciones gramaticales, es evidente que los lectores no infieren tal cosa del uso del término, como no concluyen que la literatura de la revolución mexicana fue escrita por hombres levantados en armas contra el Estado mexicano o la de las dictaduras por los dictadores o la de la violencia por los violentos.

Por todo ello, me parece que es más apropiado el término literatura del sicario (o de sicarios, o del sicariato) en Colombia. Los tres nombres que integran esta denominación son claros en la designación del objeto: novela (refiere a su género), sicario-sicariato (refiere a los personajes de la ficción y a su referente en lo "real"), Colombia (refiere tanto al espacio de la ficción como al lugar de ocurrencia del fenómeno histórico). Es decir, novela del sicario en Colombia designa el corpus de novelas con personajes sicarios, cuya acción (o la parte más importante de ella) se desarrolla en Colombia. Esta designación comporta un elemento esencial en la definición de dicha novelística: es una literatura cuyos protagonistas y cuyo espacio remiten a un fenómeno socio histórico específico. Esto indica que la constitución del corpus está definida por la común presencia en las ficciones que lo integran de un referente en lo "real": el sicario. Las novelas cuya anécdota se construye teniendo como eje central las peripecias del sicario y/o del fenómeno del sicariato pertenecen a este corpus. Dicho de otro modo, entiendo por novela del sicario (o del sicariato) aquella cuyo protagonista es sicario y/o cuya trama se estructura sobre las acciones de ese personaje y/o del entorno del sicariato. 


\section{Bibliografía}

Abad-Faciolince, H. (2008). "Estética y narcotráfico.” Revista de Estudios Hispánicos 42, pp. 513-518.

Álape, A. (2002). Sangre ajena. Bogotá: Planeta.

Álvarez Gardeazábal, G. (1986). El Divino. Bogotá: Plaza y Janés. (2002). Comandante Paraíso. Bogotá: Grijalbo.

Bahamón Dussán, M. (1988). El sicario. Cali: Orquídea.

Camacho Guizado, A. \& Guzmán Barney, A. (1990). Colombia, ciudad y violencia. Bogotá: Foro Nacional por Colombia.

Collazos Ó. (1997). Morir con papá. Bogotá: Seix Barral.

El-Kadi, A. (2007). "La Virgen de los sicarios y una gramática del caos." Espéculo 35, pp. 1-16.

Fernández L'Hoeste, H. (2008). "From Rodrigo to Rosario: Birth and Rise of the Sicaresca." Revista de Estudios Hispánicos 42, pp. 543-57.

(2000). "La Virgen de los sicarios o las visiones dantescas de Fernando Vallejo." Hispania 83, 4, pp.757-767.

Fonseca, A. (2009). “Cuando llovió dinero en Macondo.” Diss: Universidad de Kansas.

Franco Ramos, J. (1999). Rosario Tijeras. Colombia: Plaza y Janés.

Gaviria, V. (1991). El pelaito que no duró nada. Bogotá: Planeta.

Gossaín, J. (1981). La mala hierba. Colombia: Plaza y Janés.

Inzaurralde, G. (2007). "La ciudad violenta y su memoria. Novelas de la violencia en el fin de siglo.” Diss. Universiteit Leiden.

Jácome Liévano, M. (2006). "La novela sicaresca: exploraciones ficcionales de la criminalidad juvenil del narcotráfico." Diss. The University of Iowa.

Jaramillo, A. \& Salazar, A. (1992). Medellín: las subculturas del narcotráfico. Colombia: CINEP.

Lander, M. (2003). "The Intellectual's Criminal Discourse in Our Lady of the Assassins by Fernando Vallejo.” Discourse 25, 3, pp. 76-89.

(2007). "La voz impenitente de la 'sicaresca' colombiana.” Revista Iberoamericana LXXIII, 218, pp. 165-177.

López Cáceres, A. J. (2003). Entre la pluma y la pantalla. Reflexiones sobre literatura, cine y periodismo. Cali: Universidad del Valle.

Marañón, G. (1969). Lazarillo de Tormes (prefacio). Madrid: Espasa-Calpe.

Maupassant, G. (1971). Pedro y Juan. Navarra: Salvat.

Molina Lora, L. (2011). "Narrativa de drogas: una investigación trasantlántica en la producción cultural de España, México y Colombia.” Diss. Universidad de Ottawa.

Ortiz, C. (1991). "El sicariato en Medellín: entre la violencia política y el crimen organizado." Análisis político 14, pp. 60-73. 
Ospina, C. (2010). "Representación de la violencia en la novela del narcotráfico y el cine colombiano contemporáneo". Diss. University of Kentucky.

Otero Silva, M. (1972). Cuando quiero llorar no lloro. España: Seix Barral.

Pobutsky, A. (2010). "Romantizando al verdugo: las novelas sicarescas Rosario Tijeras y La Virgen de los sicarios." Revista Iberoamericana 232-233, pp. 567-582.

(2005). "Towards the Latin American Action Heroine: The case of Jorge Ramos' Rosario Tijeras." Source Studies in Latin American Popular Culture 24, pp. 17-35.

Ravelo, R. (1999). "Entrevista con Héctor Abad-Faciolince.” La Jornada 27, mayo.

Restrepo, L. (1993). Leopardo al sol. Bogotá: Norma

Rincón, O. (2009). "Narco.estética y narco.cultura en Narco.lombia." Nueva Sociedad 222, pp. 147-163.

Salazar, A. (1990). No nacimos pa semilla. Bogotá: CINEP.

Segura, C. (2004). "Kinismo y melodrama en La virgen de los sicarios y Rosario Tijeras." Estudios de Literatura Colombiana 14, pp. 110-35.

(2007). "Violencia y Melodrama en la novela colombiana contemporánea." América Latina Hoy, pp. 55-76.

Villoria Nolla, M. (2002). "(Sub)culturas y narrativas: representación del sicariato en La Virgen de los sicarios." Cuadernos de Literatura 8, pp. 106-14.

Walde, E. (1997). "Limpia, fija y da esplendor: el letrado y la letra en Colombia a fines del siglo XIX." Revista Iberoamericana 63, 178-179, pp. 71-83.

(2000) "La sicaresca colombiana. Narrar la violencia en América Latina." Nueva Sociedad 170, pp. 222-226.

(2001). "La novela de sicarios y la violencia en Colombia." Iberoamericana 1.3, pp. 27-40.

Waldmann, P. (2007). "Is There a Culture of Violence in Colombia?" Terrorism \& Political Violence 19.4, pp. 593-609.

Weakley, R. (2005). "Sangre ajena, el testimonio de un sicario." Estudios de Literatura Colombiana 16, enero-junio, pp.143-159. 